Research Article, Issue 4
Analytical Methods in Environmental Chemistry Journal
JMECJ

\title{
Synthesis of bismuth oxide: Removal of benzene from waters by bismuth oxide nanostructures
}

\author{
Negar Motakef Kazemia,** and Masoumeh Yaqoubi ${ }^{b}$ \\ a Department of Medical Nanotechnology, Faculty of Advanced Sciences and Technology, Tehran Medical Sciences, Islamic Azad University, \\ Tehran, Iran. \\ ${ }^{b}$ Department of Nanochemistry, Faculty of Pharmaceutical Chemistry, Tehran Medical Sciences, Islamic Azad University, Tehran, Iran.
}

\section{A R T I C L E I N F O:}

Received 15 Sep 2019

Revised form 11 Nov 2019

Accepted 30 Nov 2019

Available online 26 Dec 2019

\section{Keywords:}

Bismuth oxide nanostructures,

Synthesis,

Benzene removal,

Waters,

Liquid-micro solid phase extraction

\begin{abstract}
A B S T R A C T
In this research, the bismuth oxide $\left(\mathrm{Bi}_{2} \mathrm{O}_{3}\right)$ nanostructures were prepared via chemical method at $90{ }^{\circ} \mathrm{C}$ for $3 \mathrm{~h}$. the results samples were characterized by Fourier transform infrared (FTIR) for determination of functional groups, X-ray diffraction (XRD) for evaluation of crystal structure, dynamic light scattering (DLS), scanning electron microscope (SEM) for presentation of morphology and size, energy-dispersive X-ray spectroscopy (EDS) for determination of chemical composition, and diffuse reflection spectroscopy (DRS) for ultraviolet (UV) blocking. Also, the $\mathrm{Bi}_{2} \mathrm{O}_{3}$ nanostructures were used for benzene extraction from waters in $\mathrm{pH}=5-7$. By procedure, $30 \mathrm{mg}$ of $\mathrm{Bi}_{2} \mathrm{O}_{3}$ mixed with hydrophobic ionic liquid ([HMIM][PF6]) and injected to water samples. After shaking and centrifuging, benzene removed from water by ionic liquid-micro solid phase extraction (IL- $\mu$ SPE) and determined by gas chromatography with flame ionization detector (GC-FID). The absorption capacity and recovery was obtained $167.8 \mathrm{mg}$ per gram of $\mathrm{Bi}_{2} \mathrm{O}_{3}$ and more than $96 \%$, respectively. Based on the results, the bismuth oxide nanostructures were observed with rod morphology and the diameter of nanometer. The antibacterial activities of the samples were determined against Salmonella using inhibition zone diameter. Based on the study, bismuth oxide nanostructures have good potential for removal of benzene from waters. By IL- $\mu$ SPE method, the results validated by spiking of samples
\end{abstract}

\section{Introduction}

Nanotechnology has attracted a great attention in very interesting applications in various fields [1,2]. Today, the nanostructured metal oxides have much attention of researchers actively engaged in various scientific due to their interesting properties and potential applications $[3,4]$. One of applied materials is the nanostructures with nanometer-scale rod morphology [5]. Bismuth oxide nanostructure is

\footnotetext{
${ }^{*}$ Corresponding Author: Negar Motakef Kazemi Email: motakef@iaups.ac.ir https://doi.org/10.24200/amecj.v2.i04.79
}

one of a good candidate of metal oxide for different applications such as immunosensor [6], gas sensor [7], photocatalyst [8], catalyst [9], preparation of nanostructures [10], photovoltaic [11], biomedical [12, 13], antibacterial effect [14], X-ray shielding [15], optical properties [16], white-light LEDs [17], and magnetic properties [18]. The common methods of bismuth nanostructures synthesis include solution [19], solution combustion [20], solvothermal [21], hydrothermal [22], laser ablation [23], green synthesis [24], sol-gel [25], flame spray pyrolysis [26], thermal decomposition [27], vapor phase deposition [28], and sputtering 
deposition [29]. There are different polymorphs of bismuth oxide including $\alpha-\mathrm{Bi}_{2} \mathrm{O}_{3}, \beta-\mathrm{Bi}_{2} \mathrm{O}_{3}, \gamma-\mathrm{Bi}_{2} \mathrm{O}_{3}$, $\delta-\mathrm{Bi}_{2} \mathrm{O}_{3}, \varepsilon-\mathrm{Bi}_{2} \mathrm{O}_{3}$, and $\omega-\mathrm{Bi}_{2} \mathrm{O}_{3}$ which related to the temperature of their formation. Thestablepolymorph is monoclinic $\alpha-\mathrm{Bi}_{2} \mathrm{O}_{3}$ in low temperature and cubic $\delta$ - $\mathrm{Bi}_{2} \mathrm{O}_{3}$ in high temperature [30]. The increase of temperature was caused the decrease of tetragonal $\beta-\mathrm{Bi}_{2} \mathrm{O}_{3}$ structure and the show monoclinic $\alpha-\mathrm{Bi}_{2} \mathrm{O}_{3}$ in XRD patterns [31]. The ultraviolet light can be caused the increase of risk for skin cancer and ocular damage. The UV radiation included three regions UV-A (320-400 nm), UV-B (280-320 nm), and UV-C (180-280 nm). The earth's atmosphere shields the more harmful UV-C and greater than $99 \%$ of UV-B radiation. The UV-A blocking is very important to prevention from hazardous effects of exposure to direct sunlight [32]. Recently, the bismuth oxide was reported as UV-absorber application [33]. Antibacterial activity is another application of bismuth oxide nanoparticles against some pathogenic Gram-negative bacteria [14]. Also, bismuth oxide was used for removal VOCs, BTEX from waters by analytical chemistry. In the present study, bismuth oxide nanostructures were synthesized by chemical method for application of UV blocking and antibacterial activity. In addition, the bismuth oxide $\left(\mathrm{Bi}_{2} \mathrm{O}_{3}\right)$ nanostructures were used for benzene extraction from waters by IL- $\mu$ SPE. Ionic liquid caused to collected solid phase which was extracted by $\mathrm{Bi}_{2} \mathrm{O}_{3}$ in optimized $\mathrm{pH}$.

\section{Experimental}

\subsection{Materials}

All chemicals used were analytical grade. Materials including bismuth nitrate $\left(\mathrm{Bi}\left(\mathrm{NO}_{3}\right)_{3}\right)$, nitric acid $\left(\mathrm{HNO}_{3}\right)$, and sodium hydroxide $(\mathrm{NaOH})$ were purchased from Merck (Darmshtadt Germany). All aqueous solutions were prepared in deionized water (DW, Millipore). The bismuth oxide $\left(\mathrm{Bi}_{2} \mathrm{O}_{3}\right)$ nanostructures syntheses by Azad University. Benzene (CAS N: 71-43-2; $\mathrm{C}_{6} \mathrm{H}_{6}$ ) and ionic liquid of 1-Hexyl-3-methylimidazolium hexafluorophosphate ([HMIM][PF6]; CAS N:304680-35-1) purchased from Sigma Aldrich.
Five calibration solutions of benzene were prepared and the approximate concentrations of benzene were $0.5,1.0,5.0,10$ and $50 \mathrm{mg} \mathrm{L}^{-1}$. The other chemicals with high purity $(99 \%)$ were purchased from Sigma (Germany).

For analysis of benzene, gas chromatography based on flame ionization detector (GC-FID) and air sample loop injection (ASL) was used (Netherland). The Agilent 7890A GC can accommodate up to three detectors identified as front detector, back detector, and auxiliary detector. The FID detector chosen was selected for benzene analysis in gas/ liquid. Before injection, Slide the plunger carrier down until it is completely over the syringe plunger, and tighten the plunger thumb screw until fingertight. The injector temperature was adjusted to $200^{\circ} \mathrm{C}$ and the detector temperature at $250^{\circ} \mathrm{C}$. The $\mathrm{GC}$ oven temperature was programmed from $30^{\circ} \mathrm{C}$ to $220^{\circ} \mathrm{C}$ which was held for $10 \mathrm{~min}$. Hydrogen as the carrier gas was used at a flow rate of $1.0 \mathrm{~mL}$ $\min ^{-1}$ with split ratio of 1:100.

\subsection{Characterization}

The bismuth oxide nanostructures were characterized by Fourier transform infrared spectroscopy, X-ray diffraction, dynamic light scattering, scanning electron microscope, energydispersive X-ray spectroscopy, and diffuse reflection spectroscopy. FTIR spectra were recorded on a Shimadzuir 460 spectrometer in a $\mathrm{KBr}$ matrix in the range of $400-4000 \mathrm{~cm}^{-1}$. XRD pattern was performed for evaluation of crystalline structure using a Philips Company X'pert diffractometer utilizing $\mathrm{Cu}-\mathrm{Ka}$ radiation (ASENWARE, AWXBN300, China). DLS was reported the size and size distribution of nanoparticles (ZEN314, England). SEM was investigated the morphology (KYKY, EM3200, China). EDS was evaluated the elemental and chemical analysis (ASK SEM-CL View VIS, Oxford instruments, UK). DRS was investigated for light absorption and UV blocking properties of nanocomposite (UV2550, Shimadzu). 
The antibacterial activity was evaluated using disk diffusion method against Salmonella Gramnegative bacteria, strains ATCC 1231, procured from Islamic Azad University.

\subsection{Synthesis of bismuth oxide nanostructures}

Bismuth oxide nanostructures were prepared via chemical method based on schematic reaction as follows (Formula):

$2 \mathrm{BiNO}_{3}+6 \mathrm{NaOH} \underset{3 \mathrm{~h}}{\stackrel{90^{\circ} \mathrm{c}}{\longrightarrow}} \mathrm{Bi}_{2} \mathrm{O}_{3}+6 \mathrm{NaNO}_{3}+3$

In a typical reaction, $0.97 \mathrm{~g}(0.2 \mathrm{mmol})$ bismuth nitrate was solved in $1 \mathrm{ml}$ nitric acid, and $9 \mathrm{ml}$ deionized water. Then, $100 \mathrm{ml}$ sodium hydroxide $\left(0.1 \mathrm{~mol} / \mathrm{L}^{-1}\right)$ was added to the resulting solution [8]. The reactants were sealed under reflux and stirred at $90{ }^{\circ} \mathrm{C}$ for $3 \mathrm{~h}$. Then, the reaction mixture was cooled to room temperature, and separated by centrifugation. The crystals were washed with deionized water to remove residual salt, and dried in a vacuum oven at $80^{\circ} \mathrm{C}$ for $5 \mathrm{~h}$.

\subsection{Procedure}

The bismuth oxide nanostructures based on IL- $\mu$ SPE method was used for extraction of benzene from waters. By procedure, $30 \mathrm{mg}$ of bismuth oxide $\left(\mathrm{Bi}_{2} \mathrm{O}_{3}\right)$ nanostructures mixed with $0,2 \mathrm{~g}$ of 1-Hexyl-3-methylimidazolium hexafluorophosphate ([HMIM][PF6] and diluted with $0.2 \mathrm{~mL}$ of pure acetone. Then the mixture was injected into $10 \mathrm{~mL}$ of water sample or benzene standard samples with different concentration (1-100 mg L-1). The cloudy solution shacked for $5 \mathrm{~min}$ and after centrifuging for $3 \mathrm{~min}$ (3500rpm), the upper solution (water or standard solution) was determined by GC-FID. After benzene extraction by IL- $\mu$ SPE procedure, the recoveries of proposed method were measured with the ratio of initial/final concentration of benzene (signal peak area) before determined with GC-FID (Equation EQ1). In addition, adsorption capacity and removal efficiency (RE) was calculated by equation EQ2 and EQ3. $\mathrm{A}$ is the initial concentration of benzene in solution and $\mathrm{B}$ is final concentration of benzene which determinate by GC-FID in waters. The adsorption capacity of benzene $\left(\mathrm{mg} \mathrm{g}^{-1}\right)$ and, the removal efficiency of benzene (\%) was shown in EQ2 and EQ3. The $\mathrm{C}_{\mathrm{i}}$ $\left(\mathrm{mg} \mathrm{L}^{-1}\right)$ and $\mathrm{C}_{\mathrm{f}}\left(\mathrm{mg} \mathrm{L}^{-1}\right)$ are the concentration of benzene before and after extraction procedure, Vs (L) is the sample volume, and $\mathrm{M}(\mathrm{g})$ is the amount of $\mathrm{Bi}_{2} \mathrm{O}_{3}$.

$$
\begin{aligned}
& \text { Recovery }=\frac{A}{B} \times 100 \\
& A C=\frac{\left(C_{i}-C_{f}\right) \times V S}{M} \\
& R E(\%)=\frac{C_{i}-C_{f}}{C_{i}} \times 100 \\
& \text { 3. Results and Discussion } \\
& \text { 3.1. Fourier transforms infrared }
\end{aligned}
$$

\subsection{Fourier transforms infrared}

FTIR spectra of bismuth oxide nanostructures were recorded in the range of $400-4000 \mathrm{~cm}^{-1}$ with $\mathrm{KBr}$ pellets (Fig. 1). The $\mathrm{O}-\mathrm{H}$ stretching vibrations appear at $3421 \mathrm{~cm}^{-1}$. The peak at $1400 \mathrm{~cm}^{-1}$ is related to $\mathrm{C}-\mathrm{O}$ vibrations due to organic solvent. The peak at $435 \sim 505 \mathrm{~cm}^{-1}$ is originated from the metal-oxygen (Bi-O) bond. Fourier transform infrared result is

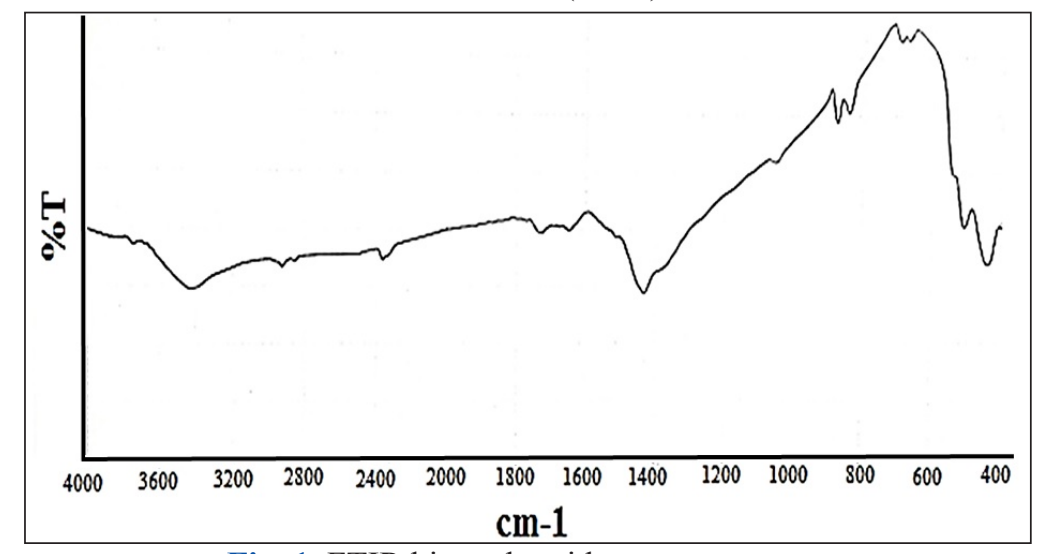

Fig. 1. FTIR bismuth oxide nanostructures. 
similar to a previously reported pattern [25].

\subsection{X-ray diffraction}

XRD measurement was used to determine the crystalline structure of bismuth oxide nanostructures in $2 \theta$ range 5 to $80^{\circ}$ (Fig. 2). The sharp peak observed at $2 \theta$ around $28^{\circ}$, and all diffraction peaks can be indexed the monoclinic $\alpha-\mathrm{Bi}_{2} \mathrm{O}_{3}$ (JCPDS card No. 41-1449). XRD result is similar to a previously reported pattern [8].

\subsection{Dynamic light scattering}

The dynamic light scattering was used to find out the size and distribution diagram of nanoparticles (Fig. 3). DLS results presented two peaks at 900 $\mathrm{nm}$ and $17 \mu \mathrm{m}$ with narrow distribution at room temperature. The observation of two peaks confirms that the nanostructure is rod shaped.

\subsection{Scanning electron microscope}

The size and morphology structures of samples were studied using SEM that shown rod-shaped with an average diameter of $500 \mathrm{~nm}$, and the length of $11 \mu \mathrm{m}$ (Fig. 4). SEM result confirmed the DLS result.

\subsection{Energy-dispersive X-ray spectroscopy}

EDS was used to evaluate the chemical composition of bismuth oxide nanostructures. This analysis was clearly showed the identification strong peaks of bismuth (Bi) and oxygen (O) elements. Based on the result the absorption peaks were exhibited at $2.4,3.2,10.8$, and $11.8 \mathrm{keV}$, which illustrated a typical absorption of the metallic bismuth. The energy-dispersive $\mathrm{X}$-ray spectroscopy and mapping of bismuth oxide nanostructures were carried out for elemental analysis (Fig. 5).

\subsection{Diffuse reflection spectroscopy}

DRS absorption spectra of bismuth oxide nanostructures showed UV blocking in three Ultraviolet: UV-A, UV-B, and UV-C (Fig 6). Based on DRS result, the absorption peak was observed $90 \%$ ultraviolet in range of 200-400 nm. Based on teh result, bismuth oxide nanostructures are good candidates as UV blocking for research development.

\subsection{Antibacterial activity}

The antibacterial activity was measured against Salmonella as Gram-negative bacteria by disk diffusion method for bismuth oxide nanostructures with concentration $0.01 \mathrm{~g}(\mathrm{~mL})^{-1}$. The zone inhibition was examined approximately $8.6 \mathrm{~mm}$. The cell wall of Gram-negative bacterium is composed a thin layer of peptidoglycan surrounded by a membranous structure called the outer membrane. The presence of carboxylic groups causes to the negative charge of bacterial cells at biological $\mathrm{pH}$. The main mechanisms of antibacterial activity are

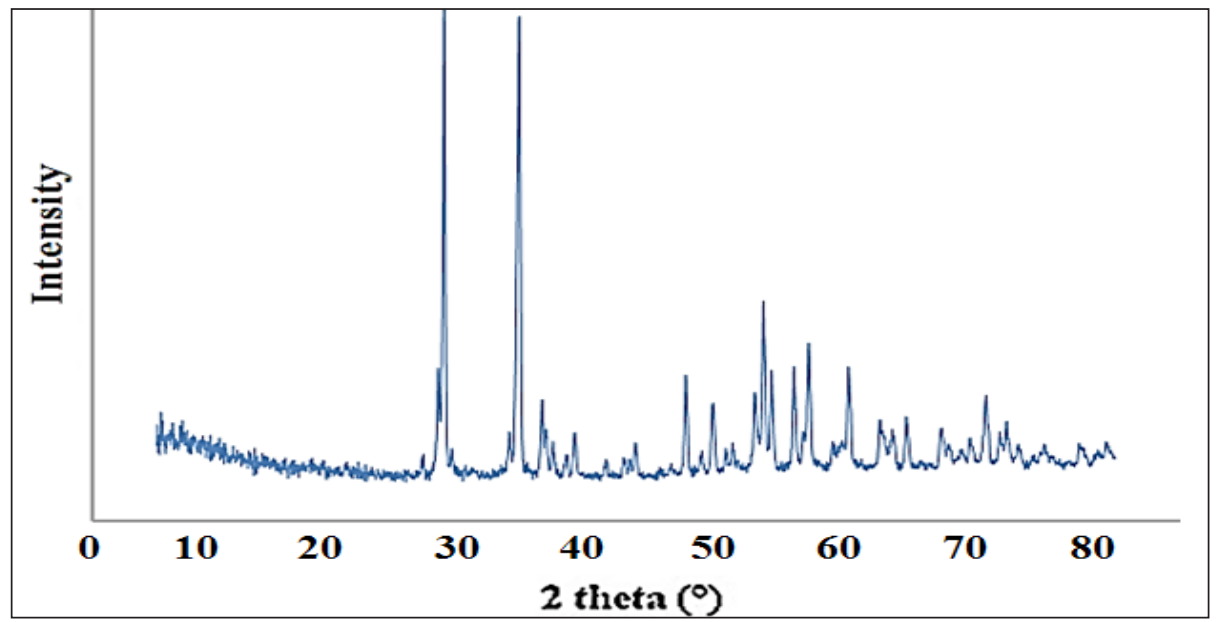

Fig. 2. XRD bismuth oxide nanostructures. 

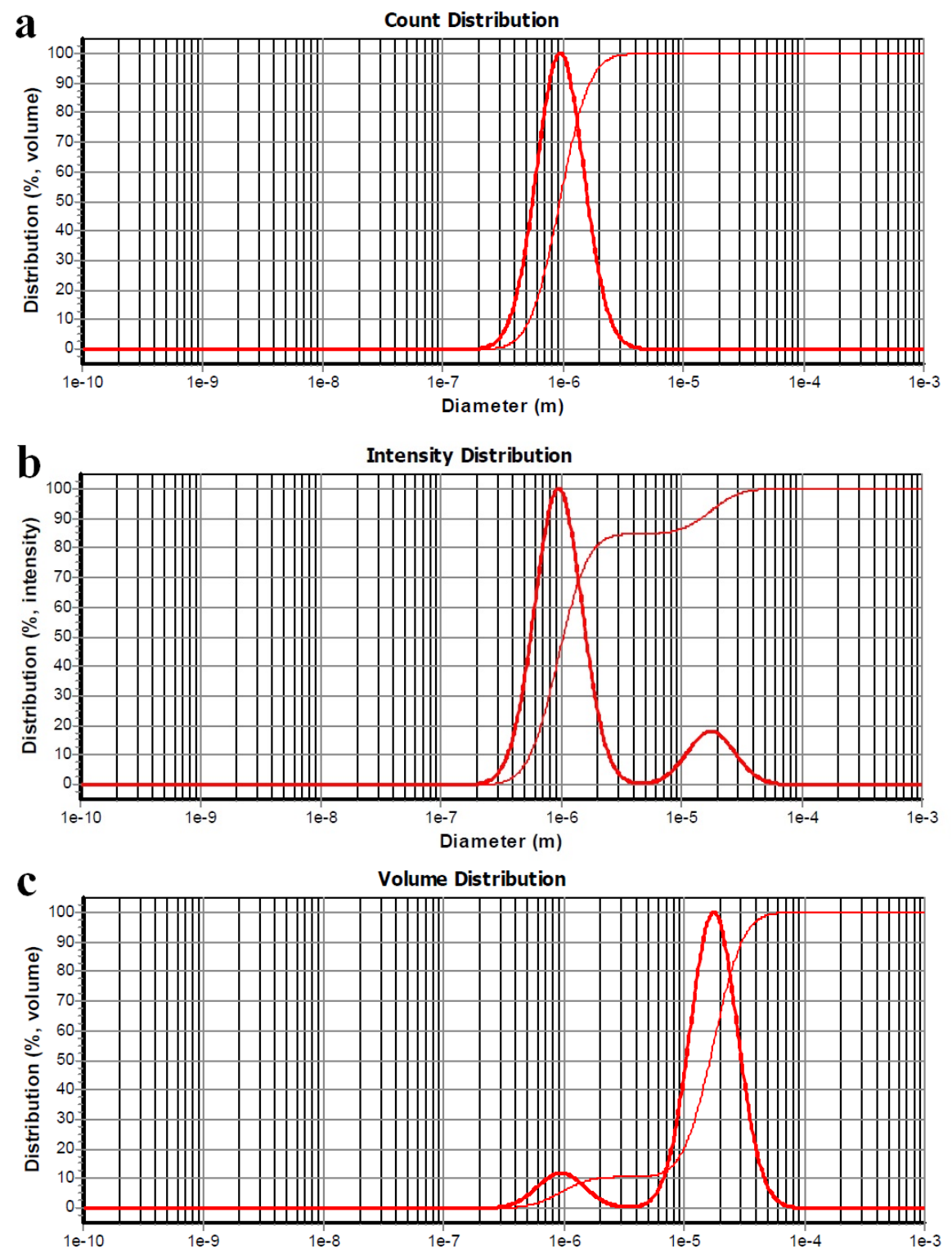

Fig. 3. DLS bismuth oxide nanostructures based on a) count, b) intensity, and c) volume.
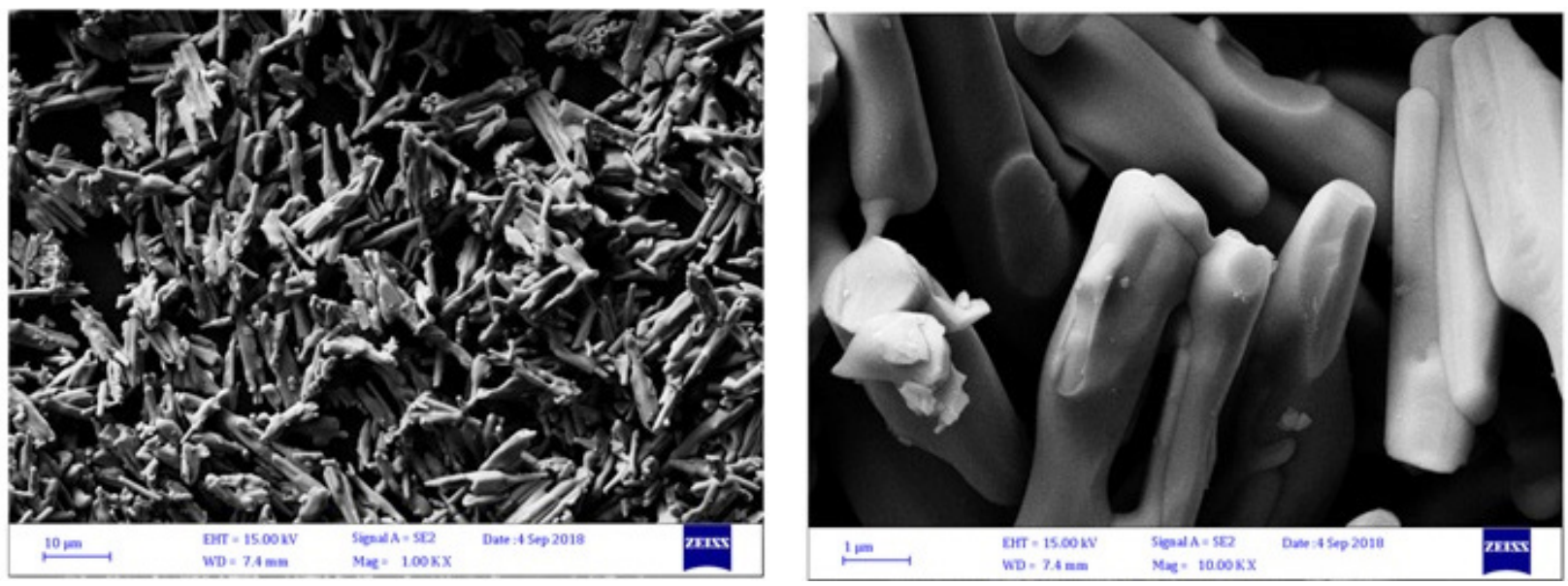

Fig. 4. SEM bismuth oxide nanostructures in different scale bar. 
electrostatic forces and adhesion of the opposite charges of Gram-negative bacterium and bismuth oxide nanostructures. Based on teh result, bismuth oxide nanostructures are good candidates as antibacterial activity for research development.

\subsection{Optimizing and validation}

The IL- $\mu$ SPE procedure based on the bismuth oxide $\left(\mathrm{Bi}_{2} \mathrm{O}_{3}\right)$ nanostructures was used for extraction of benzene in water and wastewater samples. For increasing of efficient recoveries, all parameters such as, $\mathrm{pH}$, sorbent mass, sample volume, adsorption capacity were studied and optimized. The $\mathrm{pH}$ of water sample has a main role for adsorption

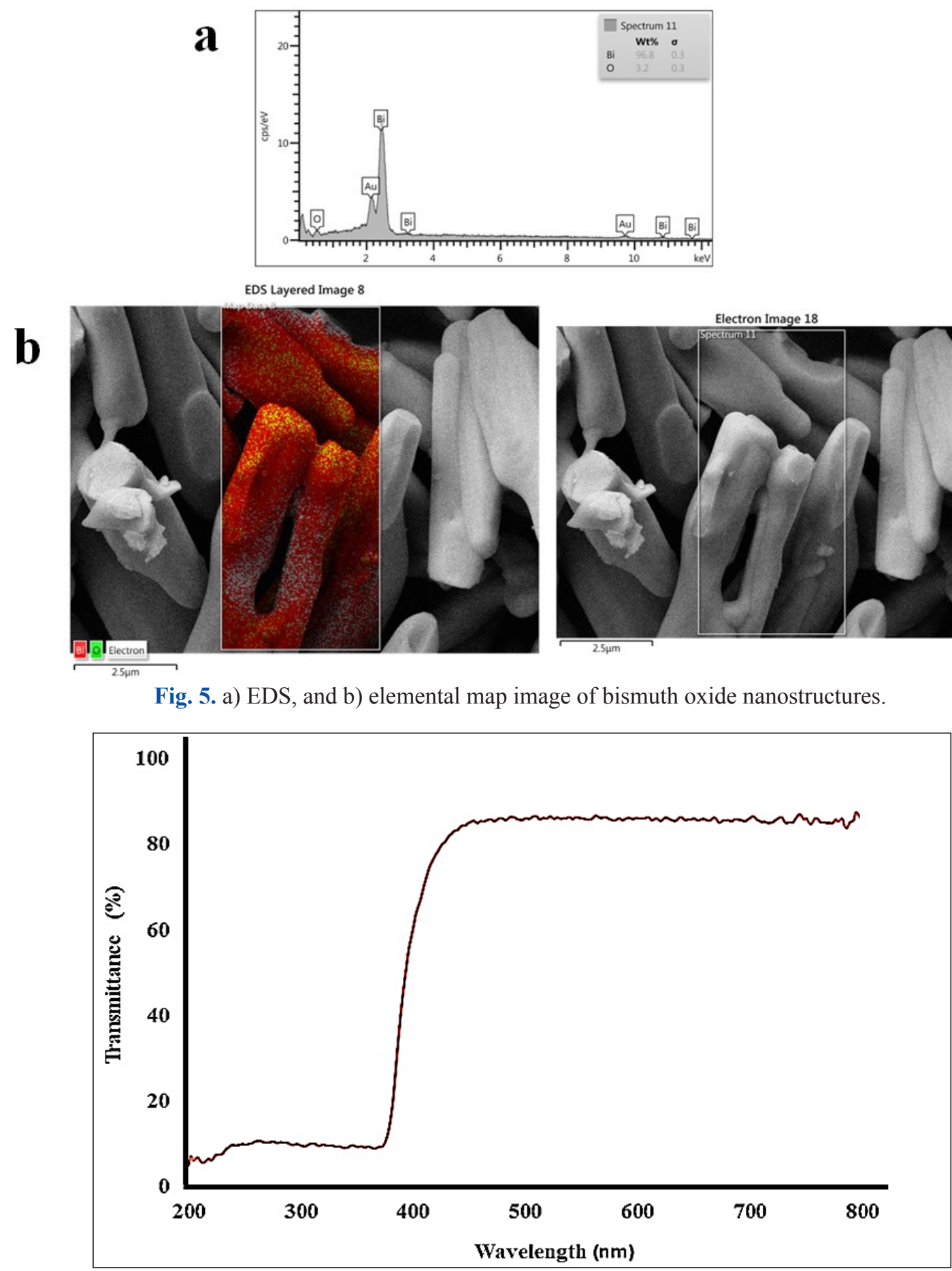

Fig. 6. DRS bismuth oxide nanostructures. 
of benzene in water and wastewater by IL- $\mathrm{Bi}_{2} \mathrm{O}_{3}$ by IL- $\mu$ SPE. The effect of $\mathrm{pH}$ range (2-11) on the extraction of benzene was studied containing $1 \mathrm{mg}$ $\mathrm{L}^{-1}$ and $10 \mathrm{mg} \mathrm{L}^{-1}$ of $\mathrm{C}_{6} \mathrm{H}_{6}$. The results showed, the recovery of extraction for benzene were decreased at $\mathrm{pH}$ ranges $(7<\mathrm{pH}<5)$ So, $\mathrm{pH}$ of 5-7 was selected as optimized $\mathrm{pH}$ for benzene extraction in waters (Fig. 7). By IL- $\mu$ SPE method, the amount of $\mathrm{Bi}_{2} \mathrm{O}_{3}$ and ILwas optimized for extraction benzene in water and wastewater samples. Therefore, 5-50 $\mathrm{mg}$ of $\mathrm{Bi}_{2} \mathrm{O}_{3}$ and 0.05-0.4 $\mathrm{g}$ of IL was used and optimized. Based on results, more than $25 \mathrm{mg}$ $\mathrm{Bi}_{2} \mathrm{O}_{3}$ and $0.15 \mathrm{~g}$ of IL can be extracted benzene in water samples in optimized $\mathrm{pH}$. So, $30 \mathrm{mg}$ and 0.2 g was selected as optimum value for $\mathrm{Bi}_{2} \mathrm{O}_{3}$ and IL, respectively (Fig.8). The sample volume effected on the extraction recoveries of benzene in water samples at $\mathrm{pH}=5-7$. The different sample volumes from 1 to $20 \mathrm{~mL}$ (1-10 $\mathrm{mgL}^{-1}$ benzene) were used benzene extraction in water samples by IL- $\mu$ SPE procedure. The results had good recoveries less than $15 \mathrm{~mL}$ of water samples. Therefore, $10 \mathrm{~mL}$ was used as the optimal sample volume by proposed procedure (Fig.9).

\section{Conclusions}

The bismuth oxide nanostructures synthesized by chemical method. The formation of nanostructures

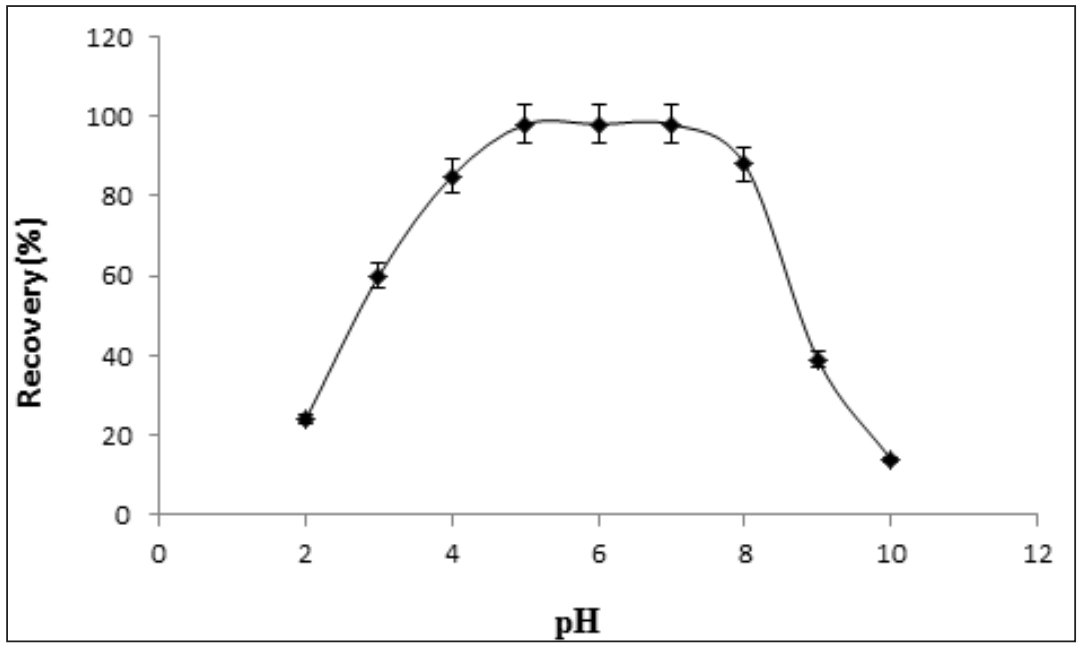

Fig. 7. The effect of $\mathrm{pH}$ on benzene extraction in water sample by IL- $\mu \mathrm{SPE}$

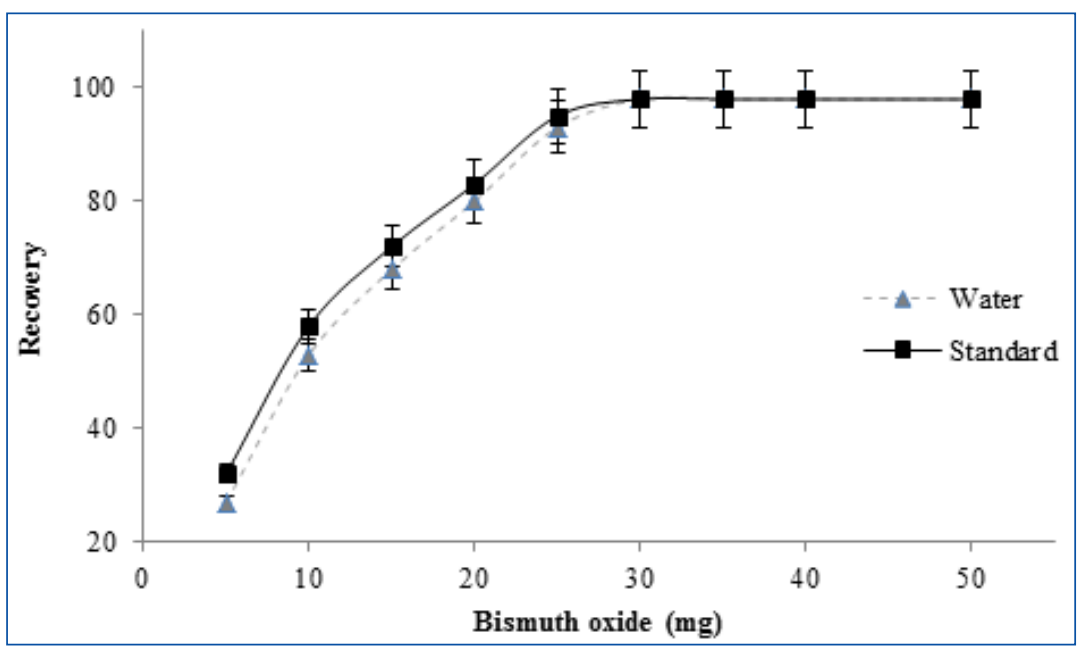

Fig. 8. The effect of bismuth oxide on benzene extraction in water sample by IL- $\mu$ SPE 


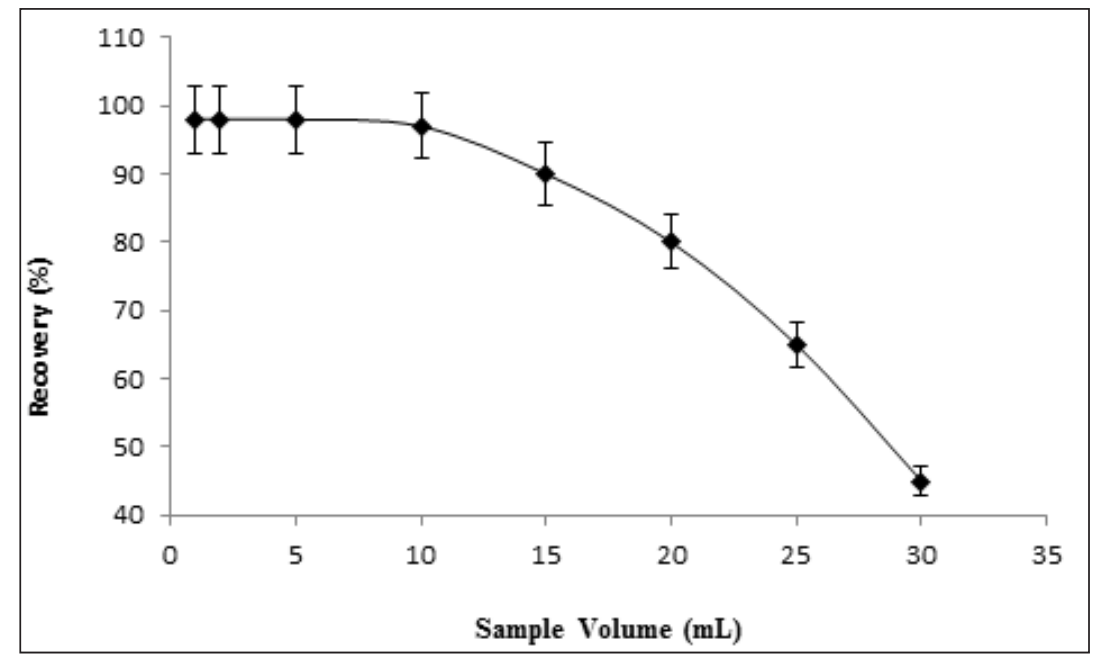

Fig. 9. The effect of Sample volume on benzene extraction in water sample by IL- $\mu$ SPE

was emphasized by DLS with narrow distribution and SEM with rod morphology. XRD confirmed the monoclinic $\alpha-\mathrm{Bi}_{2} \mathrm{O}_{3}$ crystalline structure for bismuth oxide nanostructures. In this study, benzene was extracted from water samples based on $\mathrm{IL}-\mathrm{Bi}_{2} \mathrm{O}_{3}$ by IL- $\mu \mathrm{SPE}$ procedure at $\mathrm{pH}=5-7$. The absorption capacity and mean of extraction efficiency for $\mathrm{Bi}_{2} \mathrm{O}_{3}$ was obtained $167.8 \mathrm{mg}$ per gram and almost $96 \%$, respectively. Also, we successfully observed UV blocking, and antibacterial activity applications of bismuth oxide nanostructures. These properties can be resulted to many advantages in the future with more safety and less toxicity to human health.

\section{References}

[1] M.R. Mehmandoust, N. Motakef-Kazemi, F. Ashouri, Nitrate adsorption from aqueous solution by metal-organic framework MOF-5, Iran. J. Sci. Technol. Trans A-Sci., 43 (2019) 443-449.

[2] B. Miri, N. Motakef-Kazemi, S.A. Shojaosadati, A. Morsali, Application of a nanoporous metal organic framework based on iron carboxylate as drug delivery system, Iran. J. Pharm. Res., 7 (2018) 1164-1171.

[3] S. Hajiashrafi, N. Motakef Kazemi, Preparation and evaluation of $\mathrm{ZnO}$ nanoparticles by thermal decomposition of MOF-5, Heliyon 5 (2019) e02152.
[4] N. Motakef-Kazemi, S.A. Shojaosadati, A. Morsali, In situ synthesis of a drug-loaded MOF at room temperature, Micropor. Mesopor. Mater., 186 (2014) 73-79.

[5] N. Motakef-Kazemi, S.A. Shojaosadati, A. Morsali, Evaluation of the effect of nanoporous nanorods $\mathrm{Zn}_{2}$ (bdc) ${ }_{2}$ (dabco) dimension on ibuprofen loading and release, J. Iran. Chem. Soc., 13 (2016) 12051212.

[6] P.R. Solanki, J. Singha, B. Rupavali, S. Tiwari, B.D. Malhotra, Bismuth oxide nanorods based immunosensor for mycotoxin detection, Mater. Sci. Eng. C 70 (2017) 564-571.

[7] X. Gou, R. Li, G. Wang, Z. Chen, D. Wexler, Roomtemperature solution synthesis of $\mathrm{Bi}_{2} \mathrm{O}_{3}$ nanowires for gas sensing application, Nanotechnol., 20(2009) 495-501.

[8] W. Raza, M.M. Haque, M. Muneer, T. Harada, M. Matsumura, Synthesis, characterization and photocatalytic performance of visible light induced bismuth oxide nanoparticle, J. Alloys Compd., 648 (2015) 641-650.

[9] P. Malik, D. Chakraborty, $\mathrm{Bi}_{2} \mathrm{O}_{3}$-catalyzed oxidation of aldehydes with t-BuOOH, Tetrahedron Lett., 51(2010) 3521-3523.

[10] H.T. Fan, S.S. Pan, X.M. Teng, C. Ye, G.H. Li, L.D. Zhang, $\delta-\mathrm{Bi}_{2} \mathrm{O}_{3}$ thin films prepared by reactive sputtering: Fabrication and characterization, Thin 
Solid Films., 513 (2006) 142-147.

[11] WE. Mahmoud, A.A. Al-Ghamdia, Synthesis and properties of bismuth oxide nanoshell coated polyaniline nanoparticles for promising photovoltaic properties, Polym. Adv. Technol., 22 (2011) 877-881.

[12] MJ. Oviedo, OE. Contreras, Y. Rosenstein, R. Vazquez-Duhalt, Z.S. Macedo, GG. CarbajalArizaga, G.A. Hirata, New bismuth germanate oxide nanoparticle material for biolabel applications in medicine, J. Nanomater., 2016 (2016) 1-10.

[13] M. Abudayyak, E. Oztas, M. Arici, G. Ozhan, Investigation of the toxicity of bismuth oxide nanoparticles in various cell lines. Chemosphere., 169 (2017) 117-123.

[14] AMN. Jassim, S.A. Farhan, J.A.S. Salman, K.J. Khalaf, M.F. Al-Marjani, M.T. Mohammed, Study the antibacterial effect of bismuth oxide and tellurium nanoparticles, Int. j. Chem. Boil. Sci., 1 (2015) 81-84.

[15] H. Shirkhanloo, M. Saffari, S.M. Amini, M. Rashidi, Novel semisolid design based on bismuth oxide $\left(\mathrm{Bi}_{2} \mathrm{O}_{3}\right)$ nanoparticles for radiation protection, Nanomed. Res. J., 2 (2017) 230-238.

[16] S. Condurache -Bota, V. Tiron, M. Praisler, Highly transparent bismuth oxide thin films deposition: Morphology-Optical properties correlation studies, J. Optoelectron Adv. Mater., 17 (2015) 1296-1301.

[17] Y.C. Chu, G.J. Lee, C.Y. Chen, S.H. Ma, J.J. Wu, T.L. Horng, K.H. Chen, J.H. Chen, Preparation of Bismuth Oxide Photocatalyst and Its application in white-light LEDs, J. Nanomater., 2013 (2013) 596324.

[18] A. Panda, R. Govindaraj, R. Mythili, G. Amarendra, Formation of bismuth iron oxide based core-shell structures and their dielectric, ferroelectric and magnetic properties, J. Mater. Chem. C 7 (2019) 1280-1291.

[19] F. Xia, X. Xu, X. Li, L. Zhang, L. Zhang, H. Qiu, W. Wang, Y. Liu, J. Gao, Preparation of bismuth nanoparticles in aqueous solution and its catalytic performance for the reduction of 4-nitrophenol,
Ind. Eng. Chem. Res., 53 (2014) 10576-10582.

[20] J. La, Y. Huang, G. Luo, J. Lai, C. Liu, G. Chu, Synthesis of bismuth oxide nanoparticles by solution combustion method, Particul. Sci. Technolo., 31 (2012) 287-290.

[21] J. Wu, F. Qin, Z. Lu, H.J. Yang, R. Chen, Solvothermal synthesis of uniform bismuth nanospheres using poly(N-vinyl-2-pyrrolidone) as a reducing agent, Nanoscale Res. Lett., 6 (2011) 66.

[22] Z.A. Zulkifli, K.A. Razak, W.N.W.A. Rahman, S.Z. Abidin, Synthesis and characterisation of bismuth oxide nanoparticles using hydrothermal method: the effect of reactant concentrations and application in radiotherapy, J. Phys. Chem. Solid., 1082 (2018) 012103.

[23] L. Torrisi, L. Silipigni, N. Restuccia, S. Cuzzocrea, M. Cutroneo, F. Barreca, B. Fazio, G. Di Marco, S. Guglielmino, Laser-generated bismuth nanoparticles for applications in imaging and radiotherapy, J. Phys. Chem. Solid., 119 (2018) 6270.

[24] P. Nazari, M.A. Faramarzi, Z. Sepehrizadeh, M.A. Mofid, R.D. Bazaz, A.R. Shahverdi, Biosynthesis of bismuth nanoparticles using Serratia marcescens isolated from the Caspian Sea and their characterization, IET Nanobiotechnol., 6 (2012) 58-62.

[25] M. Mallahi, A. Shokuhfar, M.R. Vaezi, A. Esmaeilirad, V. Mazinani, Synthesis and characterization of bismuth oxide nanoparticles via sol-gel method, Am. J. Eng. Res., 3 (2014) 162165.

[26] L. Mädler, S.E. Pratsinis, Bismuth oxide nanoparticles by flame spray pyrolysis, J. Am. Ceram. Soc., 5 (2004) 1713-1718.

[27] S. Schulz, S. Heimann, C. Wölper, W. Assenmacher, Synthesis of bismuth pseudo cubes by thermal decomposition of $\mathrm{Bi}_{2} \mathrm{Et}_{4}$, Chem. Mater., 24 (2012) 2032-2039.

[28] L. Kumari, J.H. Lin, Y.R. Ma, Synthesis of bismuth oxide nanostructures by an oxidative metal vapour phase deposition technique, Nanotechnol., 18 
(2007) 295605.

[29] B. Sirota, J. Reyes-Cuellar, P. Kohli, L. Wang, M.E. McCarroll, S.M. Aouadi, Bismuth oxide photocatalytic nanostructures produced by magnetron sputtering deposition, Thin Solid Film., 520 (2012) 6118-6123.

[30] M. Mehring, Molecules to bismuth oxide-based materials: Potential homo- and heterometallic precursors and model compounds, Coord. Chem. Rev., 251 (2007) 974-1006.

[31] J. Hou, C. Yang, Z. Wang, W. Zhou, S. Jiao, H. Zhu, In situ synthesis of $\alpha-\beta$-phase heterojunction on $\mathrm{Bi}_{2} \mathrm{O}_{3}$ nanowireswith exceptional visible-light photocatalytic performance, Appl. Catal. B 142 (2013) 504-511.

[32] S. Hajiashrafi, N. Motakef-Kazemi, Green synthesis of zinc oxide nanoparticles using parsley extract, Nanomed. Res. J., 3 (2018) 44-50.

[33] D. Perez-Mezcua, R. Sirera, R. Jimenez, I. Bretos, C. De Dobbelaere, A. Hardy, M.K.V. Baelc, M. Lourdes Calzada, A UV-absorber bismuth(III) Nmethyldiethanolamine complex as a lowtemperature precursor for bismuth-based oxide thin films, J. Mater. Chem. C 2 (2014) 8750-8760. 